\title{
An Activity-Dependent Neurotrophin-3 Autocrine Loop Regulates the Phenotype of Developing Hippocampal Pyramidal Neurons before Target Contact
}

\author{
Hassan Boukhaddaoui, Victor Sieso, Frederique Scamps, and Jean Valmier \\ Institut National de la Santé et de la Recherche Médicale U-432, Universite Montpellier II, 34095 Montpellier, \\ Cedex 5, France
}

Neurotrophin-3 (NT-3), its cognate receptor trkC, and voltagegated calcium channels are coexpressed by embryonic pyramidal neurons before target contact, but their functions at this stage of development are still unclear. We show here that, in vitro, anti-NT-3 and anti-trkC antibodies blocked the increase, and NT-3 reversed the decrease in the number of calbindin$\mathrm{D}_{28 \mathrm{k}}$-positive pyramidal neurons induced by, respectively, calcium channel activations and blockades. Similar results were obtained with single-neuron microcultures. In addition, voltagegated calcium channel inhibition downregulates the extracellular levels of NT-3 in high-density cultures. Moreover, electrophysiological experiments in single-cell cultures reveal a tetrodotoxin-sensitive spontaneous electrical activity allowing voltage-gated calcium channel activation. The mouse NT-3 $(-/-)$ mutation decreases by $40 \%$ the number of developing calbindin- $\mathrm{D}_{28 \mathrm{k}}$-positive pyramidal neurons, without affecting neuronal survival, both in vitro and in vivo. Thus, present results strongly support that an activity-dependent autocrine NT-3 loop provides a local, intrinsic mechanism by which, before target contact, hippocampal pyramidal-like neurons may regulate their own differentiation, a role that may be important during early CNS differentiation or after adult target disruption.

Key words: calcium channels; neurotrophin; hippocampus; pyramidal-like neuron; development; autocrine
Neurons require continuous stimulation by specific signals to survive and develop (Pettmann and Henderson, 1998). Survival, growth, and phenotypic differentiation are regulated by similar signaling molecules. Among them, nerve growth factor (NGF), brain-derived neurotrophic factor (BDNF), and neurotrophin-3 (NT-3), neurotrophin-4/5 comprise the mammalian neurotrophin gene family (Davies, 1994; Barbacid, 1995; Lewin and Barde, 1996). Work on NGF has led to the classical neurotrophic factor hypothesis that postulates that, in the developing peripheral nervous system (PNS), trophic factors produced and released by target cells (retrograde release) regulate the survival, differentiation, and maintenance of the neurons that innervate them during and after synaptogenesis. However, recent studies have shown that neurotrophins may also be transported in anterograde direction (Altar and DiStefano, 1998) and that autocrine growth factor functions are important for early embryonic differentiation and adult neuronal survival in the PNS (Wright et al., 1992; Acheson et al., 1995).

Neurotrophins and their receptors are also widely expressed in the developing CNS. For example, NGF is abundantly expressed in the hippocampus in vivo and supported the survival of some afferent basal forebrain cholinergic neurons (Chen et al., 1997). However, little is known about the source and regulation of

\footnotetext{
Received April 13, 2001; revised Aug. 31, 2001; accepted Sept. 5, 2001.

This work was supported by the Institut National de la Santé et de la Recherche Medicale and the Montpellier II University. We thank G. Dayanithi, M. Desarmenien, C. Henderson, and A. Represa for critical reading of this manuscript, P. Ernfors for NT-3 (-/-) mice, and S. Gaboyard, S. Mallie, and M. C. Rousset for technical assistance.

Correspondence should be addressed to Jean Valmier, Institut National de la Santé et de la Recherche Médicale U432, Universite Montpellier II, Place Eugene Bataillon, 34095 Montpellier, Cedex 5, France. E-mail: jvalmier@crit. univ-montp2.fr.

Copyright (ㄷ) 2001 Society for Neuroscience $\quad 0270-6474 / 01 / 218789-09 \$ 15.00 / 0$
}

growth factors that promote developmental survival and differentiation of other central neurons. Although it has not yet been demonstrated that autocrine trophic factors can regulate neuronal development and plasticity in the CNS, autocrine loops have been suspected for many central neurons coexpressing both growth factors and their receptors (Davies and Wright, 1995).

There is also considerable evidence that electrical activity regulates neuronal differentiation and survival. Recent studies have shown that neurotrophins are synthesized and secreted in an activity-dependent manner by hippocampal neurons (for review, see Lo, 1995; Thoenen, 1995) and that neurotrophins mediate the effects of voltage-activated calcium channel (VGCC) activation on the survival, morphology, and phenotype of developing central neurons (Ghosh et al., 1994; Marty et al., 1996).

After their last mitosis and before target contact [embryonic day 17 (E17)], a subpopulation of rat hippocampal pyramidal-like neurons begin to express calbindin- $\mathrm{D}_{28 \mathrm{k}}$ phenotype (Enderlin et al., 1987; Mattson et al., 1991), a specific pattern of functional VGCCs (Tanaka et al., 1995; Boukhaddaoui et al., 2000), and NT-3 and its cognate receptor trkC, both in vivo and in vitro (Collazo et al., 1992; Ip et al., 1993; Vicario-Abejon et al., 1995). Interestingly, the activation and blockade of VGCCs, respectively, increase and decrease the number of calbindin- $\mathrm{D}_{28 \mathrm{k}}$ positive pyramidal-like neurons in vitro (Boukhaddaoui et al., 2000). During the same developmental period, exogenous NT-3 upregulates the number of calbindin- $\mathrm{D}_{28 \mathrm{k}}$-positive trkCexpressing E17 hippocampal pyramidal-like neurons in vitro (Collazo et al., 1992; Ip et al., 1993; Vicario-Abejon et al., 1995).

By using high-density hippocampal cultures and specific antiNT-3 and anti-trkC antibodies, we show here that L- and Q-type channel activations upregulate NT-3/trkC signaling, which in turn controls the increase in the number of calbindin- $\mathrm{D}_{28 \mathrm{k}}$-positive trkC-expressing pyramidal-like neurons in vitro. Analysis of NT-3 
knock-out mice confirms that NT-3 regulates in vivo the calbindin$\mathrm{D}_{28 \mathrm{k}}$ phenotype of hippocampal neurons during late embryonic stages. To differentiate between autocrine or paracrine action of NT-3, we developed a single-hippocampal neuron culture assay. Our results strongly support a model in which an activitydependent autocrine NT-3 loop mediates the differentiation of developing hippocampal calbindin- $\mathrm{D}_{28 \mathrm{k}}$-positive pyramidal-like neurons before target contact.

\section{MATERIALS AND METHODS}

Animals. Rat embryonic hippocampal neurons were obtained from timed pregnant Sprague Dawley rats after $17 \mathrm{~d}$ of gestation (E17). The care and use of rats and mice conformed to institutional policies and guidelines. Mutation of the mouse NT-3 locus was generated by homologous recombination as described by Ernfors et al. (1990a), and heterozygous progeny were identified by Southern blotting. For in vitro studies using BALB/c strain pups at E16, each mouse embryo was processed separately according to the following protocol.

Dissociation procedure. Briefly, rat hippocampi were dissected, and cells were dissociated by treatment with a trypsin $(0.025 \%$; Life Technologies, Cergy Pontoise, France) DNase (100 U/ml; Sigma, St. Quentin Fallavier, France) mixture $\left(10 \mathrm{~min}\right.$ at $\left.37^{\circ} \mathrm{C}\right)$ and mechanical trituration using Pasteur pipettes with fire-polished tips (Banker and Cowan, 1977; Boukhaddaoui et al., 2000). Cells were centrifuged $(400 \times g, 5 \mathrm{~min})$ and resuspended in Neurobasal (Life Technologies) culture medium supplemented with 2\% B27 (Life Technologies) and $2 \mathrm{~mm}$ glutamine (Life Technologies).

High-density cultures. Four-well plastic dishes (16 mm; Nunc Polylabo, Strasbourg, France) were prepared with a coverslip coated for at least 1 $\mathrm{hr}$ at $37^{\circ} \mathrm{C}$ with poly-D,L-ornithine $(0.5 \mathrm{mg} / \mathrm{ml}$; Sigma $)$, followed by an incubation with laminin $(5 \mu \mathrm{g} / \mathrm{ml}$; Sigma) overnight. Two hours before cell plating, laminin was discarded and replaced by DMEM plus $10 \%$ calf fetal serum (Life Technologies). Freshly dissociated cells were seeded at $1.5-3 \times 10^{4}$ cells per well in the supplemented Neurobasal medium and maintained at $37^{\circ} \mathrm{C}$ in a Forma Scientific (Marietta, OH) humidified incubator, under $6.5 \% \mathrm{CO}_{2}$. All test products were added after $15 \mathrm{hr}$ of incubation and renewed $48 \mathrm{hr}$ after.

Single-neuron microcultures. The isolated cells from E17 rat hippocampus were conveniently diluted to obtain a plating of one cell per well of a 96-multiwell dish (Nunc Polylabo), precoated as exposed above. Individual wells were scored for the presence of a single neuron 12-15 hr after plating, and the same wells were then restored for the presence of calbindin- $\mathrm{D}_{28 \mathrm{k}}$-positive neurons up to $6 \mathrm{~d}$ later. Only the wells that had a single neuron present both at the beginning of treatment and after 6 days in vitro (DIV) were included in this analysis (control, $n=100$ wells; anti-trkC polyclonal antibody, $n=98$ wells; anti-NT-3 polyclonal antibody, $n=195$ wells; nitrendipine, $n=110$ wells; agatoxin-IVA, $n=105$ wells from two separate experiments).

Growth factors and antibody experiments. NT-3 (Human recombinant) was purchased from Tebu (Le Perray en Yvelines, France), reconstituted in distilled water as stock concentrations, added to cultures $24 \mathrm{hr}$ after plating, and replaced every $48 \mathrm{hr}$. Blocking antibody against NT-3 was purchased from Chemicon (Euromedex, Souffelweyersheim, France). Blocking antibody against trkC was from Santa Cruz Biotechnologies (Tebu). According to the supplier, anti-trkC and anti-NT-3 do not cross-react with, respectively, NGF or BDNF and trkA or trkB when specificity was assessed by Western blotting. The absence of crossreactivity of these antibodies to the related neurotrophins NGF and BDNF was also examined in primary cultures of $1 \mathrm{~d}$ postnatal mice dorsal root ganglion (DRG) neurons whose survival is enhanced by the presence of these neurotrophins. Compared with untreated cultures ( $<10 \%$ survival at 2-3 DIV) (for method, see Valmier et al., 1993), cultures treated with NGF $(10 \mathrm{ng} / \mathrm{ml})$ and BDNF $(10 \mathrm{ng} / \mathrm{ml})$ showed increased cell survival ( $>90 \%$ survival; $n=3$ ). Addition of either anti-NT-3 or anti-trkC in the presence of NGF and BDNF was without effect on dorsal root ganglion neuron survival. Thus, these antibodies blocked NT-3 signaling (see Results) without interfering with signaling by closely related neurotrophins. The amounts of anti-NT-3 and antitrkC antisera added to the cultures were, respectively, 10 and $0.4 \mu \mathrm{g} / \mathrm{ml}$, and specificity was determined using $10 \mathrm{ng} / \mathrm{ml} \mathrm{NT}-3$ in the assay. The antibodies completely inhibited the increase in the number of calbindin$\mathrm{D}_{28 \mathrm{k}}$-positive neurons induced by NT-3 in hippocampal cultures.

Culture neuron counting. Multipolar pyramidal-like neurons, which constitute $>70 \%$ of the neurons in hippocampal cultures, were identified by their characteristic large and pyramidal-shaped soma having one major axon-like apical neurite and several minor, dendritic-like processes as described by Mattson et al. (1988). Calbindin- $\mathrm{D}_{28 \mathrm{k}}$-positive neurons were counted under a Zeiss (Oberkochen, Germany) photonic microscope ( $32 \times$ objective), and at least $10 \%$ of neurons in each sample were scored. Unless otherwise stated, three or four separate wells were counted per condition, and each experiment was performed in triplicate. For survival assays, neurons were stained with neurofilament antibodies (Sigma), and all neurofilament-positive cells were considered as neurons. Four wells for each of at least duplicate experiments were counted for each condition. In addition, for all calbindin- $\mathrm{D}_{28 \mathrm{k}}$ staining experiments, viable neurons were counted using phase contrast. Cells were considered to be neurons if they had a smooth soma, were round or oval, and possessed regular neurites. The findings of phase-contrast examination were consistent with those of neurofilament staining.

Immunocytochemistry of cultured cells. After $6 \mathrm{DIV}$, cells were fixed for $30 \mathrm{~min}$ with $4 \%$ paraformaldehyde in $0.1 \mathrm{M}$ phosphate buffer, $\mathrm{pH} 7.4$, treated for $5 \mathrm{~min}$ in PBS containing $0.3 \%$ Triton X-100, incubated $30 \mathrm{~min}$ in $10 \%$ normal goat serum (Sigma) in PBS, and incubated overnight at $4^{\circ} \mathrm{C}$ with anti-calbindin- $\mathrm{D}_{28 \mathrm{k}}$ polyclonal antibody $(1: 20,000$; Swant, Bellinzona, Switzerland). Anti-calbindin- $\mathrm{D}_{28 \mathrm{k}}$ monoclonal antibody was used when cells were treated with anti-trkC polyclonal or anti-NT-3 polyclonal antibodies. The cells were then incubated for $30 \mathrm{~min}$ at room temperature with the corresponding biotinylated antisera (1:200; Vector Laboratories, Valbiotech, Paris, France), followed by $1 \mathrm{hr}$ incubation at room temperature with horseradish peroxidase-coupled Vectastain ABC kit (Vector Laboratories). Staining was revealed with a diaminobenzidine solution (Vector Laboratories). Coverslips were mounted in Fluor Save Reagent (Calbiochem, Meudon, France) for counting and archiving. For all antibodies, staining was abolished by substitution of nonimmune serum for the primary antiserum (data not shown).

Fluorescent immunocytochemistry. The same procedure was used (see above), but two primary antibodies were simultaneously incubated overnight at $4^{\circ} \mathrm{C}$ : anti-calbindin- $\mathrm{D}_{28 \mathrm{k}}$ monoclonal antibody (1:5000; Swant) and anti-Neurofilament 200 polyclonal antibody (1:500; Sigma). Primary antibody fixation was detected with secondary antibodies: Cy3conjugated goat anti-mouse (1:1000; Jackson Laboratories, Euromedex) mixed with FITC-conjugated goat anti-rabbit (1:200; Jackson Laboratories). These secondary antibodies were incubated for $2 \mathrm{hr}$ at $4^{\circ} \mathrm{C}$, and immunostaining was analyzed with confocal microscopy (MRC 600; Bio-Rad, Hercules, CA). Immunostaining was specific for all antibodies because staining was abolished by substitution of nonimmune serum for the primary antiserum (data not shown).

In vivo immunohistochemistry. Newborn mice were anesthetized by intraperitoneal injection of pentobarbital and perfused with $4 \%$ paraformaldehyde and $0.2 \%$ glutaraldehyde in ice-cold $0.1 \mathrm{~m}$ phosphate buffer, $\mathrm{pH}$ 7.4. Brains were removed and post-fixed for $24 \mathrm{hr}$ at $4^{\circ} \mathrm{C}$ with $4 \%$ paraformaldehyde and then cryoprotected overnight with $20 \%$ sucrose before processing. All immunostaining was performed on freefloating $40 \mu \mathrm{m}$ sections cut using a vibratome (VT 1000E; Leica, Nussloch, Germany). The sections were first treated with $\mathrm{H}_{2} \mathrm{O}_{2}$ in methanol to suppress endogenous peroxidase activity. The immunostaining of calbindin- $\mathrm{D}_{28 \mathrm{k}}$ was performed as indicated above.

For the counting of calbindin- $\mathrm{D}_{28 \mathrm{k}}$-positive neurons, we focused on a $\left(200 \times 200 \mu \mathrm{m}^{2}\right)$ square containing the CA1 region of the developing hippocampus. Counts were done, in double blind, at $200 \times$ magnification in every fifth section for each hippocampus. The total number of pyramidal neurons in the above area was assessed by counterstaining with 10 $\mu \mathrm{g} / \mathrm{ml}$ Hoechst 33342 (Sigma) at room temperature for $10 \mathrm{~min}$. Data were expressed by the mean number of calbindin- $\mathrm{D}_{28 \mathrm{k}}$-immunoreactive neurons of NT-3 $(+/+)$ and NT-3 $(-/-)$ groups.

For the qualitative analysis of calbindin- $\mathrm{D}_{28 \mathrm{k}}$-positive neuron morphology, we used fluorescent immunohistochemistry to better delineate the neuronal morphology (soma and neurites). The immunostaining of calbindin- $\mathrm{D}_{28 \mathrm{k}}$ was performed as indicated above.

Analysis of NT-3 levels. Emax immunoassay kit (Promega, Charbonnieres, France) has been designed for sensitive and specific detection of NT-3 in an antibody sandwich format as described by the manufacturer. Nevertheless, to improve the sensitivity, we use a modification of the conventional ELISA methodology termed ELISA-in situ described by Balkowiec and Katz (2000). Briefly, microtiter plates (96 wells, MaxiSorp; Nunc Polylabo) were first UV sterilized for $1 \mathrm{hr}$ and coated with anti-NT-3 polyclonal antibody in carbonate buffer, $\mathrm{pH} 9.7$, overnight at $4^{\circ} \mathrm{C}$. Then, plates were rinsed once with wash solution and saturated with 
blocking sample buffer according to the manufacturer. After two washes with culture medium, hippocampal neurons were plated in the anti-NT3 -coated wells at $10^{4}$ cells per well density. Four hours after seeding, the calcium channel blockers were added. The extracellular levels of NT-3 was measured at 3 DIV. At this time, the plates were extensively washed to remove all cells. Wells were controlled with bright-field microscopy to ensure cell elimination. The subsequent steps were performed according to the protocol of the manufacturer. Absorbance values were read at 450 $\mathrm{nm}$ in a plate reader (Rosys Anthos 2000), and the NT-3 content of each well was determined according to standard curves plotted from predetermined concentrations of NT-3. All data are averages of four separate measurements, and the experiment was itself repeated three times.

Electrophysiological recordings. Spontaneous electrical activity was recorded on isolated single hippocampal pyramidal-like neurons. Cells from E17 rat hippocampus were seeded on large plastic dishes precoated ( $35 \mathrm{~mm}$; Nunc) at a density 50 cells per dish. For these experiments, care was taken to select by eye an isolated neuron in the field of a $10 \times$ objective $(100 \times$ magnification). Usually, there was one neuron in the visual field. In a series of experiments, to avoid any potential synaptic contacts, cells were diluted as described for the single-neuron microcultures but seeded on eight wells $(10 \times 10 \mathrm{~mm}$; Lab-Tek; Nunc $)$ to allow the access for electrophysiological experiments. After recordings, to identify calbindin- $\mathrm{D}_{28 \mathrm{k}}$-positive hippocampal neurons and to further support the lack of connections with possible neighboring neurons, pyramidal-like cells were stained with both neurofilament and calbindin$\mathrm{D}_{28 \mathrm{k}}$ antibodies, and their phenotype was analyzed with confocal microscopy $(n=4)$. The electrical activity was recorded extracellularly with the loose patch-clamp technique. A patch pipette (3-4 M $\Omega$ ) filled with the bathing solution (in mM: $140 \mathrm{NaCl}, 5.4 \mathrm{KCl}, 1.8 \mathrm{CaCl}_{2}, 1.5 \mathrm{MgCl}_{2}, 10$ glucose, and 10 HEPES, pH 7.4) was used to make a low-resistance seal with the neuron (from $30 \mathrm{M} \Omega$ ). Fluctuations of extracellular voltage attributable to action potentials were recorded in the $I=0$ mode of the Axopatch 200 B (Axon Instruments, Foster City, CA). The experimental parameters were controlled with a computer equipped with a DigiData 1200 analog interface (Axon Instruments). The software pClamp (version 8.01; Axon Instruments) was used for acquisition and analysis. Voltage signals were filtered at $2 \mathrm{kHz}$ and sampled at $10 \mathrm{kHz}$.

Statistical analysis. Results are expressed as percentages of calbindin$\mathrm{D}_{28 \mathrm{k}}$-positive cells in the various culture conditions, with the control taken as the $100 \%$ values. Data are expressed as mean \pm SEM. Statistical significance of difference between means was assessed with ANOVA and $t$ test, and the level of significance was set at $p<0.05$.

\section{RESULTS}

\section{Endogenous NT-3 promotes calbindin- $D_{28 k}$ expression of immature hippocampal pyramidal-like neurons in vitro}

As reported previously, in high-density dissociated cultures of E17 rat hippocampus, the number of calbindin- $\mathrm{D}_{28 \mathrm{k}}$-positive pyramidal-like neurons increased from 0 on 1 DIV to $1002 \pm$ $79 / \mathrm{cm}^{2}$ on $6 \mathrm{DIV}$, whereas there were no changes in the total number of neurons $(n=4)$ (Mattson et al., 1991; Boukhaddaoui et al., 2000). Because NT-3 is expressed by embryonic hippocampal neurons (Blondel et al., 2000), we examined the possibility that endogenous NT-3 might regulate the expression of calbindin- $\mathrm{D}_{28 \mathrm{k}}$-positive neurons in these cultures. Treatment of cultures with either anti-trkC or anti-NT-3 alone for $5 \mathrm{~d}$ reduced the number of calbindin- $\mathrm{D}_{28 \mathrm{k}}$-positive pyramidal-like neurons to, respectively, $55 \pm 12 \%(n=4)$ and $67 \pm 8 \%(n=3)$, with no changes in the total number of neurons (Fig. $1 A, B)$.

To further confirm the importance of endogenous NT-3 for the calbindin- $\mathrm{D}_{28 \mathrm{k}}$ phenotype, we used neurons from NT-3 (-/-) mice. The number of calbindin- $\mathrm{D}_{28 \mathrm{k}}$-positive pyramidal-like neurons from E16 wild-type mice represented $11 \pm 2 \%$ of the total number of neurons at 6 DIV $(n=4)$. Hippocampal cultures from NT-3 $(-/-)$ mice contained $\sim 45 \%$ fewer calbindin- $\mathrm{D}_{28 \mathrm{k}}$-positive pyramidal neurons than cultures from wild-type NT-3 $(+/+)$ embryos without difference in the total number of neurons (Fig. $1 C, D)(n=3)$. To verify that cultures derived from NT-3 $(-/-)$
A

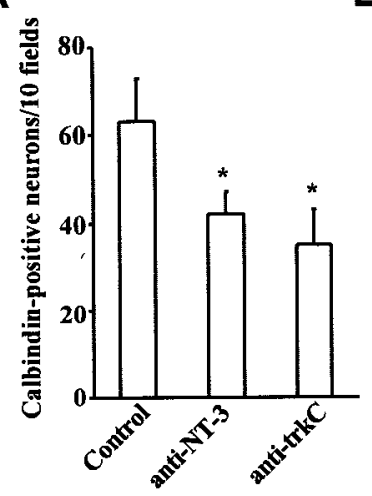

B

C
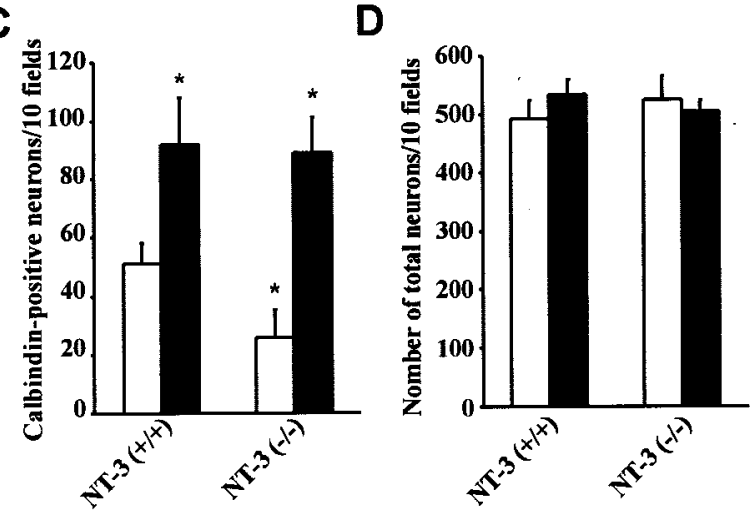

Figure 1. Endogenous NT-3 promotes the expression of calbindin- $\mathrm{D}_{28 \mathrm{k}}$ of hippocampal pyramidal-like neurons after $6 \mathrm{~d}$ in vitro. Anti-NT-3- and anti-trkC antisera inhibit the constitutive increase in the number of calbindin- $\mathrm{D}_{28 \mathrm{k}}$-positive neurons $(A)$ without affecting neuronal survival $(B)$. Number of calbindin- $\mathrm{D}_{28 \mathrm{k}}$-positive neurons $(C)$ and of total number of cells $(D)$ from hippocampal dissociated cultures from E16 mice wildtype and NT-3 (-/-) mutant embryos in the absence (white) or presence (black) of $1 \mathrm{ng} / \mathrm{ml} \mathrm{NT-3}$ after $6 \mathrm{~d}$ in vitro. ${ }^{*} p<0.01$.

embryos were not depleted of cells with the potential to express more calbindin- $\mathrm{D}_{28 \mathrm{k}}$, we treated the cultures with $1 \mathrm{ng} / \mathrm{ml} \mathrm{NT}-3$. Exogenous NT-3 brought up the number of calbindin- $\mathrm{D}_{28 \mathrm{k}}$ positive neurons to the same level, regardless of genotype (Fig. $1 C, D)(n=2)$. These observations indicate that endogenous NT-3 via its high-affinity trkC receptor contributes to the calbindin- $\mathrm{D}_{28 \mathrm{k}}$ differentiation of embryonic hippocampal pyramidal-like neurons in vitro.

\section{Endogenous NT-3 promotes calbindin- $\mathrm{D}_{28 \mathrm{k}}$ expression of immature hippocampal pyramidal-like neurons in vivo}

To determine whether the in vitro effect of NT-3 on calbindin$\mathrm{D}_{28 \mathrm{k}}$-positive pyramidal-like neuron differentiation is physiologically relevant, we performed a comparative histological study of the early postnatal [postnatal day $0(\mathrm{P} 0)$ to $\mathrm{P} 1]$ hippocampus of wild-type $(n=4)$ and NT-3 $(-/-)$ mice $(n=4)$. The total number of cells and the number of calbindin- $\mathrm{D}_{28 \mathrm{k}}$-positive pyramidal-like neurons were counted in serial sections of the CA1 hippocampus (Fig. 2A,B). There was a significant reduction $(60 \%)$ in the number of calbindin- $\mathrm{D}_{28 \mathrm{k}}$-positive neurons in NT-3 $(-/-)$ compared with wild-type mice (Fig. $2 C$ ), with no change in the total number of cells (Fig. 2D) (Ernfors et al., 1994; Klein et al., 1994). These results demonstrate that, in the absence of NT-3 signaling during the late embryonic period, a decreased propor- 

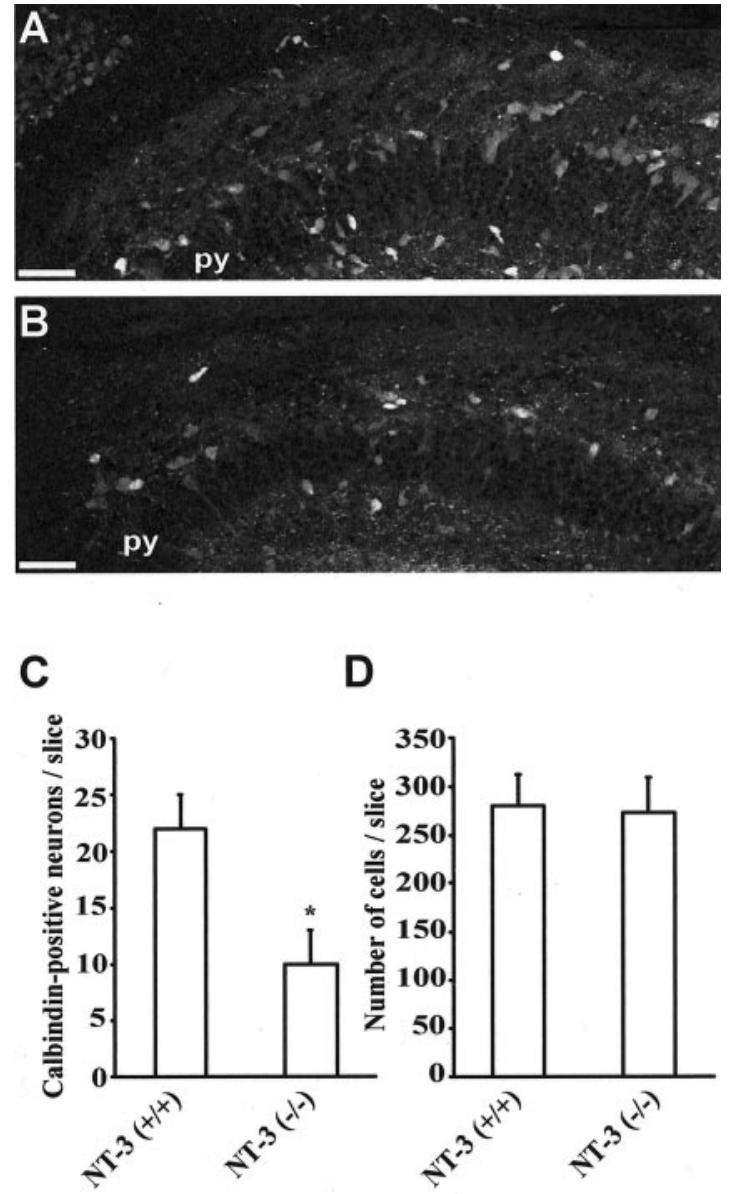

Figure 2. Endogenous NT-3 promotes the expression of calbindin- $\mathrm{D}_{28 \mathrm{k}}$ of hippocampal pyramidal-like neurons in vivo. $A, B$, Photomicrographs of equivalent cross sections of hippocampus from P0 wild-type $(A)$ and NT-3 (-/ ) mutant $(B)$ mice stained with calbindin- $\mathrm{D}_{28 \mathrm{k}}$ antisera. $p y$, Stratum pyramidale. The staining with calbindin- $\mathrm{D}_{28 \mathrm{k}}$ antibodies was lower, and pyramidal neurons appeared smaller in NT-3 $(-/-)$ than in NT-3 (+/+) mice. Scale bar, $50 \mu \mathrm{m}$. $C, D$, Quantitative analysis of the number of calbindin- $\mathrm{D}_{28 \mathrm{k}}$-positive neurons $(C)$ and the total number of neurons $(D)$ in the hippocampus derived from P0 wild-type and NT-3 $(-/-)$ mutant mice. ${ }^{*} p<0.01$.

tion of hippocampal neurons develop their calbindin- $\mathrm{D}_{28 \mathrm{k}}$ phenotype in vivo.

\section{Endogenous NT-3 mediates the effects of calcium channel activation on calbindin- $D_{28 k}$ expression of immature hippocampal pyramidal-like neurons in vitro}

We showed previously that hippocampal pyramidal-like neurons in culture express both L-type and Q-type VGCCs. Activation of these channels led to an increase in the number of calbindin- $\mathrm{D}_{28 \mathrm{k}}$ positive neurons, whereas their blockade reduced control levels (Boukhaddaoui et al., 2000). We therefore asked whether NT-3 acts upstream, downstream, or independently of $\mathrm{Ca}^{2+}$ influx through $\mathrm{Ca}^{2+}$ channels in regulating calbindin- $\mathrm{D}_{28 \mathrm{k}}$ expression.

We first asked whether the increase in the number of calbindin$\mathrm{D}_{28 \mathrm{k}}$-positive neurons after $\mathrm{KCl}$ treatment was dependent on the functions of NT-3/trkC. Anti-trkC antibodies completely inhibited the increase in the number of calbindin- $\mathrm{D}_{28 \mathrm{k}}$-positive neurons induced by daily $(1 \mathrm{hr})$ stimulation during $5 \mathrm{~d}$ with $50 \mathrm{~mm}$ $\mathrm{KCl}$ (Fig. 3A). In contrast, chronic blockade of either Q-type (by $250 \mathrm{nM} \omega$-agatoxin-IVA) or L-type $\mathrm{Ca}^{2+}$ (by $500 \mathrm{~nm}$ nitren-
A

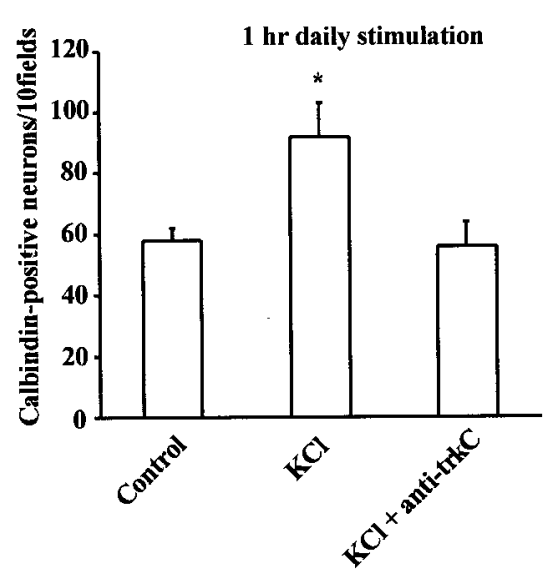

B
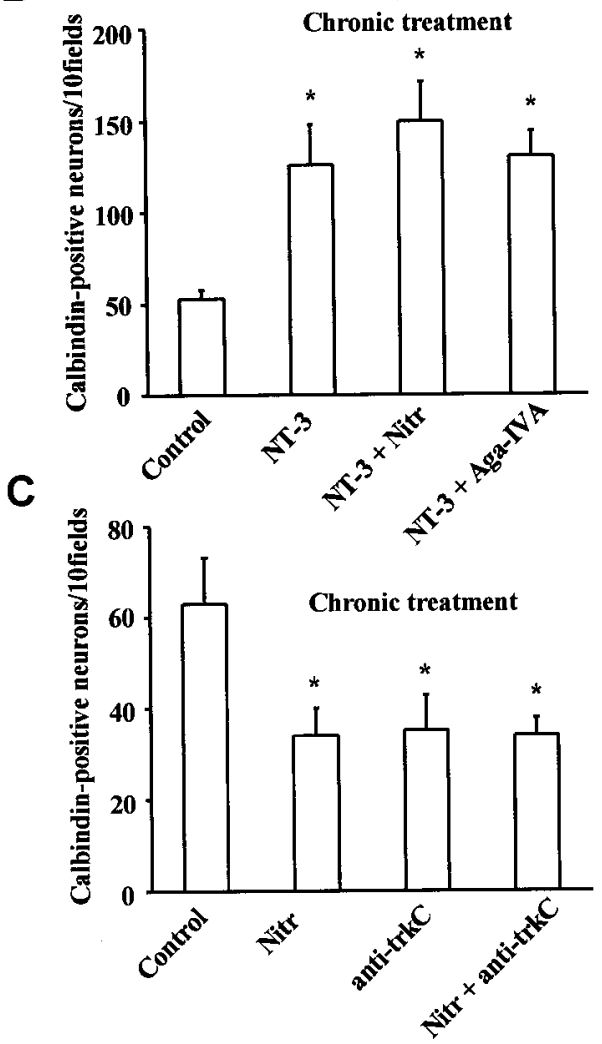

Figure 3. Endogenous NT-3 mediates the effects of calcium channel activation on the expression of calbindin- $\mathrm{D}_{28 \mathrm{k}}$ of immature hippocampal pyramidal-like neurons in vitro. Addition of anti-trkC antibodies (0.4 $\mu \mathrm{g} / \mathrm{ml})$ to the $50 \mathrm{~mm} \mathrm{KCl-depolarizing} \mathrm{medium} \mathrm{inhibited} \mathrm{the} \mathrm{increase} \mathrm{in}$ the number of calbindin- $\mathrm{D}_{28 \mathrm{k}}$-positive neurons induced by $1 \mathrm{hr}$ daily stimulation during $5 \mathrm{~d}$ with $50 \mathrm{~mm} \mathrm{KCl}(A)$. Chronic treatment for $5 \mathrm{~d}$ (1-6 DIV) with $10 \mathrm{ng} / \mathrm{ml} \mathrm{NT-3} \mathrm{induced} \mathrm{an} \mathrm{increase} \mathrm{in} \mathrm{calbindin-} \mathrm{D}_{28 \mathrm{k}}$ positive neurons. In the presence of $500 \mathrm{~nm}$ nitrendipine (Nitr) or $250 \mathrm{~nm}$ $\omega$-agatoxin-IVA, NT-3 still induced increase in calbindin- $\mathrm{D}_{28 \mathrm{k}}$-positive neurons $(B)$. Chronic treatment for $5 \mathrm{~d}$ with $500 \mathrm{~nm}$ nitrendipine, 0.4 $\mu \mathrm{g} / \mathrm{ml}$ anti-trkC alone, or both shows a similar $40 \%$ decrease in the number of calbindin- $\mathrm{D}_{28 \mathrm{k}}$-positive pyramidal neurons compared with control conditions $(C)$.

dipine) channels, or both, starting from 1 to 6 DIV, i.e., for $5 \mathrm{~d}$, failed to reduce the increase in calbindin- $\mathrm{D}_{28 \mathrm{k}}$-positive neurons induced by $10 \mathrm{ng} / \mathrm{ml} \mathrm{NT-3}$ without affecting neuronal survival (Fig. $3 B$ ). These results indicate that calbindin- $\mathrm{D}_{28 \mathrm{k}}$ expression induced by $\mathrm{Ca}^{2+}$ channel activation requires high-affinity trkC receptor activation by NT-3. 


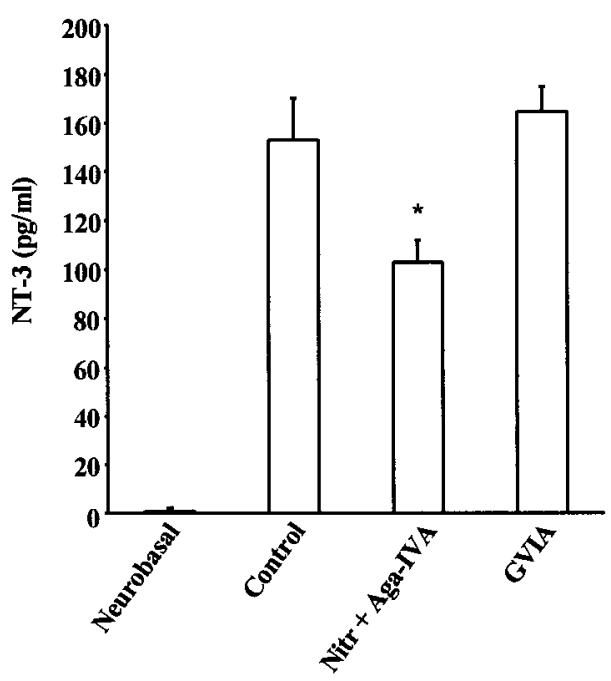

Figure 4. L- and Q-type, but not N-type, calcium channels expressed by immature hippocampal neurons regulate the extracellular levels of NT-3. Control measurements of the culture medium without cells showed no contamination with NT-3 (Neurobasal). $\omega$-Agatoxin-IVA at $250 \mathrm{~nm}$ plus $500 \mathrm{nM}$ nitrendipine during 3 DIV significantly reduced the extracellular levels of NT-3, whereas $1 \mu \mathrm{M} \omega$-conotoxin-GVIA in the same condition had no effect compared with control conditions.

To test whether $\mathrm{Ca}^{2+}$ channel and trkC activators act on the same neuronal subpopulation, we compared the chronic effects of the $\mathrm{Ca}^{2+}$ channel blocker nitrendipine and anti-trkC antibodies alone and together. Whatever the conditions used (500 nm nitrendipine and $0.4 \mu \mathrm{g} / \mathrm{ml}$ anti-trkC antibodies alone or together), a $40 \%$ decrease in the number of calbindin- $\mathrm{D}_{28 \mathrm{k}}$-positive pyramidal neurons was observed after 6 DIV compared with controls (Fig. $3 C$ ). Thus, $\mathrm{Ca}^{2+}$ influx through $\mathrm{L}$ - and Q-type $\mathrm{Ca}^{2+}$ channels, and NT-3 through trkC activation, regulate calbindin- $\mathrm{D}_{28 \mathrm{k}}$ expression in the same hippocampal pyramidal-like subpopulation in vitro.

\section{Calcium channel activation regulates the extracellular levels of NT-3 in immature hippocampal cultures}

To further analyze the relationship between VGCCs and NT-3/ trkC function in this model, we next considered the possibility that L- and Q-type VGCCs expressed by hippocampal neurons might regulate the extracellular levels of NT-3. Using a highly sensitive NT-3 ELISA assay (ELISA-in situ) (Balkowiec and Katz, 2000), the amount of extracellular NT-3 was analyzed in control conditions or in the presence of $\omega$-agatoxin-IVA-nitrendipine (to block L- and Q-type channels) or $\omega$-conotoxin-GVIA (a blocker of N-type calcium channels, which are not expressed by pyramidal neurons in the soma) (Boukhaddaoui et al., 2000) as a control. Control measurements of the culture medium without cells showed no contamination with NT-3 (Fig. 4). In control cultures of hippocampal neurons (3 DIV), significant extracellular levels of NT-3 were measured $(153 \pm 17 \mathrm{pg} / \mathrm{ml} ; n=3)$. The extracellular NT-3 concentration was lower $(103 \pm 9 \mathrm{pg} / \mathrm{ml} ; n=$ $3 ; p<0.01)$ in culture treated with $250 \mathrm{~nm} \omega$-agatoxin-IVA plus $500 \mathrm{~nm}$ nitrendipine for 3 DIV than in control conditions or in the presence of $1 \mu \mathrm{M} \omega$-conotoxin-GVIA $(165 \pm 10 \mathrm{pg} / \mathrm{ml}$ decrease; $n=2$; NS) (Fig. 4), indicating that L- and Q-type channels expressed by hippocampal neurons regulate the extracellular levels of NT-3.
Involvement of an activity-dependent autocrine loop in the effects of NT-3 on immature hippocampal pyramidal-like neurons

Although the above data showed that NT-3 regulated calbindin$\mathrm{D}_{28 \mathrm{k}}$ expression by immature hippocampal pyramidal-like neurons, they did not discriminate between a paracrine or an autocrine action of NT-3. To unequivocally demonstrate an NT-3 autocrine loop, hippocampal neurons were plated in microwells as single-cell cultures. Fifty hours after plating, single hippocampal neurons, without non-neuronal cells, were identified and used for experiments (see Materials and Methods). At 6 DIV, whatever the conditions tested, these single cultured pyramidal-like neurons were stained using calbindin- $\mathrm{D}_{28 \mathrm{k}}$ antibodies (Fig. 5A). In control conditions, $>98 \%$ of the pyramidal-like neurons cultured as single cell and present at $15 \mathrm{hr}$ in vitro survive as single cells at $6 \mathrm{DIV}$, and $20 \%$ of them become calbindin- $\mathrm{D}_{28 \mathrm{k}}$-positive. Chronic treatment with either anti-NT-3 or anti-trkC antibodies reduced the number of calbindin- $\mathrm{D}_{28 \mathrm{k}}$-positive neurons by $40 \%$ compared with control conditions, without affecting neuronal survival (Fig. 5B,C). These data suggest the existence of an NT-3 autocrine loop that mediates the induction of the calbindin- $\mathrm{D}_{28 \mathrm{k}}$ phenotype in immature hippocampal pyramidal-like neurons.

To determine whether the effects of $\mathrm{Ca}^{2+}$ channel activation also involved autocrine actions of NT-3, we used single-cell cultures in the presence or the absence of $\mathrm{L}$ - and Q-type $\mathrm{Ca}^{2+}$ channel blockers. Chronic treatment with either 500 nM nitrendipine or $250 \mathrm{nM} \omega$-agatoxin-IVA reduced the number of calbindin- $\mathrm{D}_{28 \mathrm{k}}$-positive neurons by $40 \%$ compared with control conditions, without affecting neuronal survival (Fig. 5B,C). Altogether, these data indicate that an NT-3- and trkC-expressing subpopulation of embryonic hippocampal pyramidal-like neurons regulate the development of their calbindin- $\mathrm{D}_{28 \mathrm{k}}$ phenotype after VGCC activation through an autocrine loop involving NT-3.

\section{Tetrodotoxin-sensitive spontaneous electrical activity mediates calcium channel activation of immature hippocampal pyramidal-like neurons}

To confirm that pyramidal-like neurons displayed an intrinsic spontaneous electrical activity that in turn activated VGCCs, we used the loose patch-clamp technique that offers the advantage to record extracellular electrical activity as an index of action potential, without perturbing the cell. With the very low-density culture conditions, an electrical activity was detected in most hippocampal pyramidal-like neurons tested at 3 DIV $(n=3$; one culture), 4 DIV ( $n=7$; two cultures), and $5 \operatorname{DIV}(n=4$; two cultures). Among these 14 neurons, two distinct modes of activity could be described. The most frequent mode was characterized by a sparse, irregular activity $(0.1-1 \mathrm{~Hz})$, interrupted with short periods of bursts $(3-10 \mathrm{~Hz})$ : a phasic-like activity (12 of 14 cells) (Fig. $6 C$ ). The less frequent mode was a regular pattern of activity at a $3-10 \mathrm{~Hz}$ frequency: a tonic-like activity ( 2 of 14 cells). In four experiments, after electrical activity recordings, the neuron was stained with neurofilament antibody to confirm its neuronal phenotype and the absence of cell contacts (Fig. 6A) and assayed for the presence of calbindin- $\mathrm{D}_{28 \mathrm{k}}$. At $4 \mathrm{DIV}$, one of three neurons was positive for calbindin- $\mathrm{D}_{28 \mathrm{k}}$, and at 5 DIV the hippocampal neuron stained was positive (Fig. $6 B$ ). Using single-cell microcultures, pyramidal-like neurons still displayed a phasic-like activity measured at 3 DIV ( $n=3$; one culture) (Fig. $6 D)$. Whatever the methodological approach, application of $1 \mu \mathrm{M}$ tetrodotoxin, a specific inhibitor of voltage-dependent sodium channels, inhibited the spontaneous electrical activity (four of four cells) (Fig. 6D). 
A

B
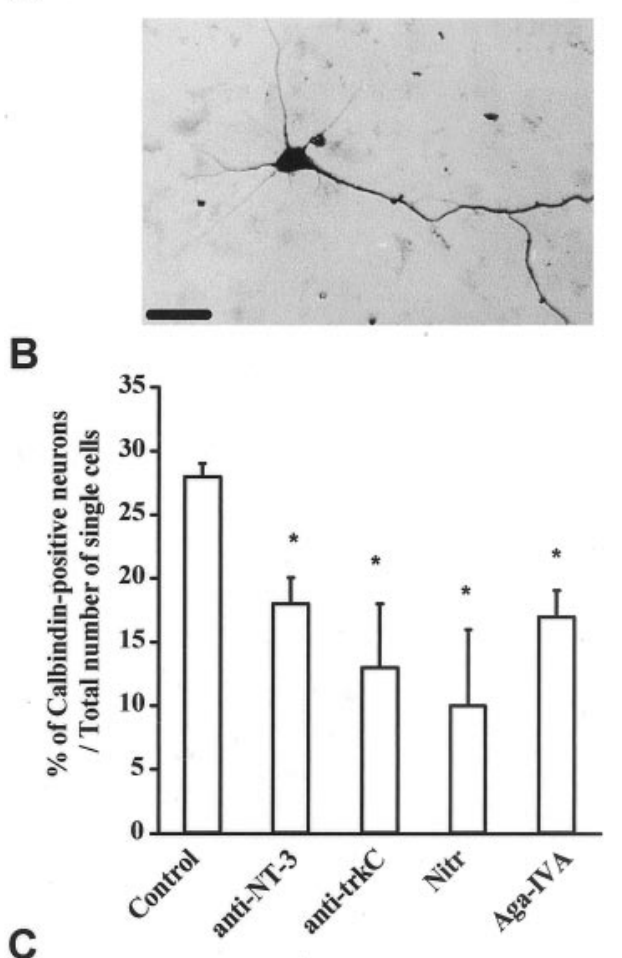

C

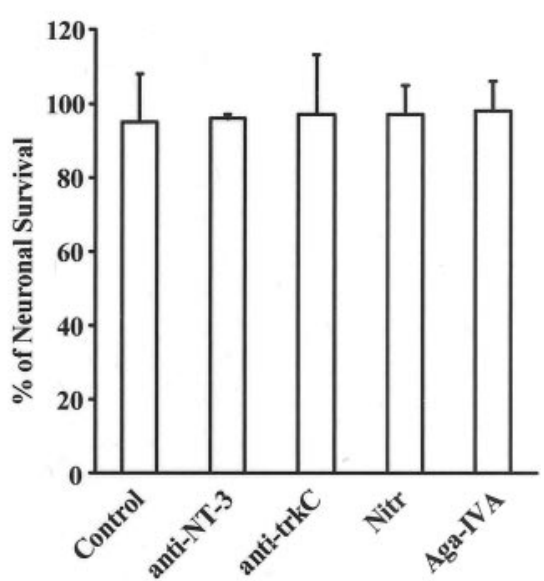

Figure 5. A calcium-dependent NT-3 autocrine loop promotes the expression of calbindin- $\mathrm{D}_{28 \mathrm{k}}$ of hippocampal pyramidal-like neurons. $A$, Bright-field micrograph of an embryonic hippocampal calbindin- $\mathrm{D}_{28 \mathrm{k}^{-}}$ positive neuron growing in microwell culture as a single cell after 6 DIV in control conditions. Scale bar, $50 \mu \mathrm{m}$. Effect of anti-NT-3 and anti-trkC antisera and nitrendipine (500 nM; nitr) and $\omega$-agatoxin-IVA (250 nM) on the percentage of calbindin- $\mathrm{D}_{28 \mathrm{k}}$-positive neurons $(B)$ and the percentage of pyramidal neurons survival $(C)$ from hippocampal neuronal cultures as single cell (control, $n=100$ wells; anti-trkC polyclonal antibody, $n=98$ wells; anti-NT-3 polyclonal antibody, $n=195$ wells; nitrendipine, $n=105$ wells; $\omega$-agatoxin-IVA, $n=110$ wells from two separate experiments). ${ }^{*} p<0.01$.

These results suggest that activation of VGCCs could be attributable to sodium-driven action potentials. To further support that these tetrodotoxin-sensitive spontaneous action potentials are responsible for the effects of VGCCs on calbindin- $\mathrm{D}_{28 \mathrm{k}}$ expression, we performed experiments aimed to demonstrate that blockade of action potential regulates this phenotype. Indeed, chronic application of $1 \mu \mathrm{M}$ tetrodotoxin to mass culture induced a $31 \pm 6 \%$ decrease in the number of calbindin- $D_{28 k}$-positive
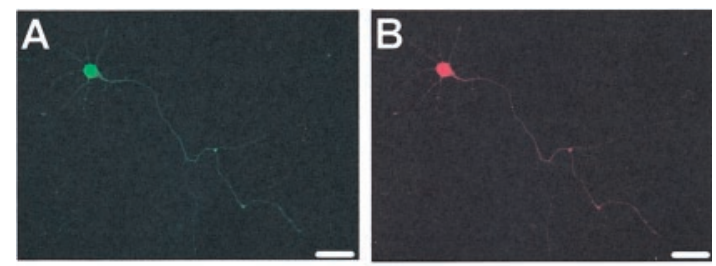

C
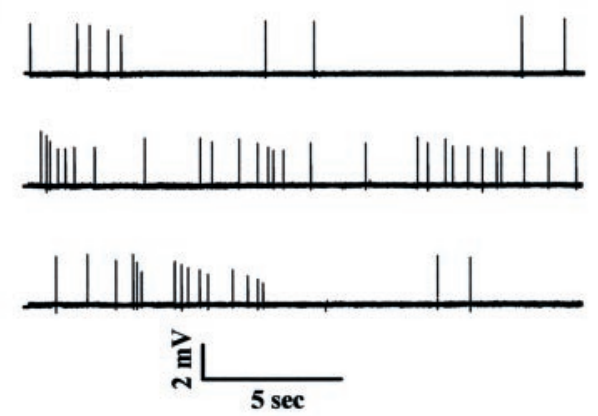

D
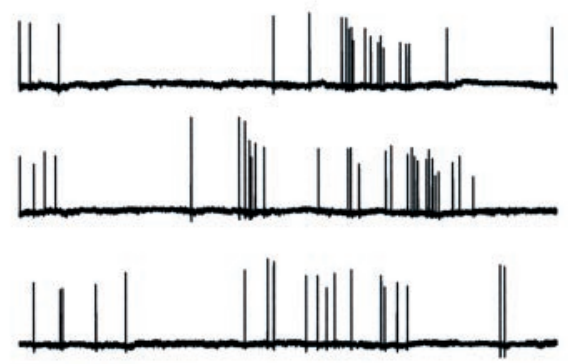

TTX $1 \mu M$

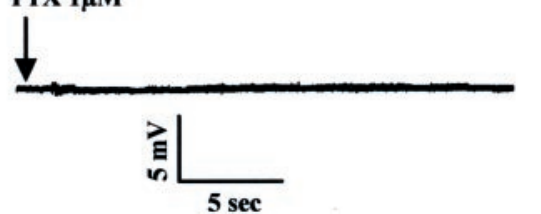

Figure 6. Single pyramidal-like neurons displayed a phasic spontaneous electrical activity. $A, B$, Bright-field micrograph of a single pyramidal-like neuron grown in very low-density culture recorded and stained at 5 DIV. Staining from the same neuron with neurofilament $(A)$ and calbindin $\mathrm{D}_{28 \mathrm{k}}$ $(B)$ antibodies. Scale bar, $25 \mu \mathrm{m}$. The corresponding electrical activity of the same neuron before staining recorded with the loose patch is shown in $C$ as upward deflections. $D$, Spontaneous electrical activity recorded at 3 DIV on a pyramidal-like neuron grown as a single-neuron microculture. Application of $1 \mu \mathrm{M}$ TTX inhibited electrical activity.

neurons compared with control conditions $(58 \pm 10$ and $39 \pm 9$ calbindin- $\mathrm{D}_{28 \mathrm{k}}$-positive neurons per 10 fields, respectively, for control and TTX treatment), whereas there were no changes in the total number of neurons (data not shown) $(n=3)$.

\section{DISCUSSION}

The modes of action of the neurotrophins in the CNS are still unclear. Here, we show that, before target contact, a subpopulation of immature hippocampal neurons (pyramidal neurons that express NT-3, trkC, and L- and Q-type calcium channels) requires for its calbindin- $\mathrm{D}_{28 \mathrm{k}}$ phenotype differentiation an activitydependent NT-3 autocrine loop. The use of single-cell microcultures demonstrate that the pathways we describe are regulated in an autocrine mode. The physiological relevance of our findings was shown in vivo by comparing the development of calbindin$\mathrm{D}_{28 \mathrm{k}}$ phenotype of wild-type and NT-3 knock-out mice. Thus, 
these data extend to the CNS the previously described neurotrophin autocrine loop function in the PNS (Acheson et al., 1995). In addition, molecules and mechanisms (sodium-dependent action potential and calcium influx through VGCCs) that regulate this autocrine loop are identified. The well known phenomenon of activity-dependent neurotrophin regulation in the CNS can thus now be described at the single neuronal level and independently of the network.

To demonstrate autocrine action by NT-3, we used a singlehippocampal neuron culture assay to isolate these neurons from any other source of NT-3. In these conditions, neurons survive and develop their calbindin- $\mathrm{D}_{28 \mathrm{k}}$-phenotype spontaneously. Addition of either NT-3- or trkC-neutralizing antibodies do not affect neuronal survival but decrease by $40 \%$ the number of calbindin- $\mathrm{D}_{28 \mathrm{k}}$-positive pyramidal-like neurons. Similar decrease was observed in high-density culture from NT-3 $(-/-)$ versus NT-3 $(+/+)$ mice, which was reversed by addition of NT-3. Hippocampal neurons from wild-type rodents express both NT-3 and trkC during the late embryonic period and develop their calbindin- $\mathrm{D}_{28 \mathrm{k}}$ phenotype in vitro with a similar pattern as they do in vivo (Enderlin et al., 1987; Maisonpierre et al., 1990; Collazo et al., 1992; Lamballe et al., 1994). Conversely, hippocampus from mutant mice lacking the NT-3 gene showed a $40 \%$ decrease in calbindin- $\mathrm{D}_{28 \mathrm{k}}$-positive neurons in vivo (present results). Altogether, these data indicate that autocrine NT-3 loop is likely to be physiologically relevant in regulating the development of calbindin- $\mathrm{D}_{28 \mathrm{k}}$ expressed by a subpopulation of hippocampal pyramidal-like neurons. During this period of development, NT-3 regulates, in addition to calbindin- $\mathrm{D}_{28 \mathrm{k}}$ phenotype, growth of pyramidal soma and neurites and formation of their excitatory synapses (Vicario-Abejon et al., 1995; Baker et al., 1998; VicarioAbejon et al., 1998). Thus, the autocrine loop we described here may, during ontogenesis, have important implications for hippocampus pyramidal neuron differentiation before target contact is established.

Among the other issues concerning autocrine loop mechanisms, one is to determine whether NT-3 acts intracellularly or whether the factor has to be secreted to act on its cognate receptor. The presence of endogenous NT-3 in the culture medium and the effects of both specific NT-3- and trkC-neutralizing antisera acting extracellularly suggest that hippocampal neurons secrete NT-3 that in turn binds trkC to regulate calbindin- $\mathrm{D}_{28 \mathrm{k}}$ expression. Unresolved issues concern whether this autocrine loop is switched off during development as suggested for autocrine BDNF loop in embryonic DRG neurons (Wright et al., 1992) and which mechanisms and molecules regulate the development of calbindin- $\mathrm{D}_{28 \mathrm{k}}$ expression in the absence of NT-3 production or binding to neurons. Our results clearly demonstrated that an NT-3 independent, parallel mechanism operates to modulate calbindin- $\mathrm{D}_{28 \mathrm{k}}$ expression. Recent findings have shown that hepatocyte growth factor (HGF) via its high-affinity receptor c-Met regulates, in vitro, calbindin- $\mathrm{D}_{28 \mathrm{k}}$ expression in embryonic hippocampal neurons and that this effect is additive with the NT-3 effect on calbindin- $\mathrm{D}_{28 \mathrm{k}}$ phenotype (Korhonen et al., 2000). Therefore, it appears that at least two different hippocampal neuronal subpopulations, expressing either trkC or c-Met, may regulate differently their calbindin- $\mathrm{D}_{28 \mathrm{k}}$ phenotype using, respectively, NT-3 and HGF.

Another important finding of the present study was the observation that $\mathrm{Ca}^{2+}$ channel activation controls this autocrine loop at the single-cell level, confirming increasing evidence that neurotrophins are crucial factors involved in activity-dependent de- velopment and plasticity of the nervous system (Thoenen, 1995). The causal link between $\mathrm{Ca}^{2+}$ influx and NT-3/trkC signaling was demonstrated by the finding that anti-trkC inhibited the development of the calbindin- $\mathrm{D}_{28 \mathrm{k}}$ phenotype induced by calcium channel activation, and, conversely, NT-3 prevented the inhibitory effect of $\mathrm{Ca}^{2+}$ channel blockers. On the other hand, the effects of NT-3 or anti-trkC application on calbindin- $\mathrm{D}_{28 \mathrm{k}}$ expression were unaffected whether $\mathrm{Ca}^{2+}$ channels and subsequent $\mathrm{Ca}^{2+}$ influx was enhanced or inhibited. These results were supported by single-cell experiments. In addition, one single hippocampal neuron was able to discharge spontaneous tetrodotoxin-sensitive action potentials that control the opening of VGCCs as judged by the inhibition of calbindin- $\mathrm{D}_{28 \mathrm{k}}$ expression under tetrodotoxin. Therefore, these data support a model in which a single neuron regulates the development of its phenotype after sodium and calcium voltage-gated ionic channel activations through an autocrine loop involving a neurotrophic factor.

Because L- and Q-type channel blockades downregulated the extracellular levels of NT-3 in high-density hippocampal cultures, this indicates that VGCCs are involved in the control of extracellular NT-3 levels. However, the observation that VGCC blockades inhibited only by $30 \%$ the levels of NT-3 (Fig. 4) but completely abolished the NT-3-dependent calbindin- $\mathrm{D}_{28 \mathrm{k}}$ phenotype (Fig. $3 C$ ) points to complex interactions in the NT-3/trkC signaling regulation by voltage-gated ionic channels. Indeed, VGCC activation may regulate neurotrophic factor synthesis, and depolarization may induce cell surface expression of trk receptor, as demonstrated respectively for BDNF (Ghosh et al., 1994) and trkB (Meyer-Franke et al., 1998; Du et al., 2000). Alternatively, there are also strong arguments for a TTX-sensitive sodiumdependent neurotrophin secretion by central and peripheral neurons (Blochl and Thoenen, 1995; Balkowiec and Katz, 2000), and we show, in the present study, that pyramidal-like hippocampal neurons generate spontaneously TTX-sensitive action potential in our culture conditions. All of these nonexclusive hypotheses are currently under investigation.

Neuronal development is traditionally thought to involve two separate phases: an early activity-independent phase before target contact and a late activity-dependent phase after synaptogenesis. It had been widely assumed that the activity of ion channels was associated only with the later when neuronal network becomes engaged in the usual form of chemical signaling and electrical activity, driven by sensory data (Katz and Shatz, 1996). However, recent findings indicate that neurons express ionic channels soon after neurogenesis, and spontaneous activity occurs independently of the normal operation of circuits (for review, see Spitzer, 1994; Komuro and Rakic, 1998; Moody, 1998). As shown previously in invertebrate muscle cells (Greaves et al., 1996) and amphibian spinal neurons (Henderson and Spitzer, 1986), the present data demonstrate that, in mammalian CNS, spontaneous electrical activity occurs in completely isolated cells and controls the normal calbindin- $\mathrm{D}_{28 \mathrm{k}}$ phenotype development of the neurons displaying this activity. As far as the origin of this sodium-dependent spontaneous electrical activity is concerned, several mechanisms can be proposed, including autapses, somatic release of neuromediators, or "pacemaker" channels. Such spontaneous electrical activity probably represents an important regulator of neuronal development before target contact and synapse formation.

The NT-3 autocrine loop that we propose to be present in hippocampal neurons may be representative of a broader phenomenon in the nervous system in which, for example, different 
subsets of developing DRG, cortical neurons, and motoneurons respond to NT-3 and coexpress both NT-3 and its cognate receptor (Ernfors et al., 1990b; Schecterson and Bothwell, 1992). Interestingly, both NT-3 and trkC are colocalized in neurons not only during development but also in adulthood, suggesting a role for autocrine loop in the maintenance and the plasticity of the mature nervous system. Such autocrine loops (Acheson et al., 1995; present results) may be also relevant for the neurotrophic factors as a whole because, for example, coexpression of BDNF (Kokaia et al., 1993; Miranda et al., 1993), HGF (Yang et al., 1998), fibroblast growth factor (Korsching, 1993), leukemia inhibitory factor (Cheng and Patterson, 1997), glial cell line-derived neurotrophic factor (Giehl et al., 1998), insulin-like growth factor (Lindholm et al., 1996), and their cognate receptors are present in different neuronal subpopulations of both the PNS and the CNS. Thus, the activity-dependent neurotrophin autocrine loop described here adds an alternate mechanism of action for this important class of molecules in the CNS and opens new areas of inquiry into neurotrophin action not only in the development and the physiology of the neuron at the single-cell level but also in the physiopathology of neurological diseases in which alterations in neutrophin, calcium channels, and calbindin- $\mathrm{D}_{28 \mathrm{k}}$ components have been demonstrated (Iacopino and Christakos, 1990; Phillips et al., 1991; Vahedi et al., 1995; Von Brederlow et al., 1995).

\section{REFERENCES}

Acheson A, Conover JC, Fandl JP, DeChiara TM, Russell M, Thadani A, Squinto SP, Yancopoulos GD, Lindsay RM (1995) A BDNF autocrine loop in adult sensory neurons prevents cell death. Nature 374:450-453.

Altar CA, DiStefano PS (1998) Neurotrophin trafficking by anterograde transport. Trends Neurosci 21:433-437.

Baker RE, Dijkhuizen PA, Van Pelt J, Verhaagen J (1998) Growth of pyramidal, but not non-pyramidal, dendrites in long-term organotypic explants of neonatal rat neocortex chronically exposed to neurotrophin-3. Eur J Neurosci 10:1037-1044.

Balkowiec A, Katz DM (2000) Activity-dependent release of endogenous brain-derived neurotrophic factor from primary sensory neurons detected by ELISA in situ. J Neurosci 20:7417-7423.

Banker GA, Cowan WM (1977) Rat hippocampal neurons in dispersed cell culture. Brain Res 126:397-425.

Barbacid M (1995) Neurotrophic factors and their receptors. Curr Opin Cell Biol 7:148-155.

Blochl A, Thoenen H (1995) Characterization of nerve growth factor (NGF) release from hippocampal neurons: evidence for a constitutive and an unconventional sodium-dependent regulated pathway. Eur J Neurosci 7:1220-1228.

Blondel O, Collin C, McCarran WJ, Zhu S, Zamostiano R, Gozes I, Brenneman DE, McKay RD (2000) A glia-derived signal regulating neuronal differentiation. J Neurosci 20:8012-8020.

Boukhaddaoui H, Sieso V, Scamps F, Vigues S, Roig A, Valmier J (2000) Q- and L-type calcium channels control the development of calbindin phenotype in hippocampal pyramidal neurons in vitro. Eur J Neurosci 12:2068-2078.

Chen KS, Nishimura MC, Armanini MP, Crowley C, Spencer SD, Phillips HS (1997) Disruption of a single allele of the nerve growth factor gene results in atrophy of basal forebrain cholinergic neurons and memory deficits. J Neurosci 17:7288-7296.

Cheng JG, Patterson PH (1997) LIF is an autocrine factor for sympathetic neurons. Mol Cell Neurosci 9:372-380.

Collazo D, Takahashi H, McKay RDG (1992) Cellular targets and trophic functions of neurotrophins-3 in the developing rat hippocampus. Neuron 9:643-656.

Davies AM (1994) The role of neurotrophins in the developing nervous system. J Neurobiol 25:1334-1348.

Davies AM, Wright EM (1995) Neurotrophic factors. Neurotrophin autocrine loops. Curr Biol 5:723-726.

Du J, Feng L, Yang F, Lu B (2000) Activity- and Ca(2+)-dependent modulation of surface expression of brain-derived neurotrophic factor receptors in hippocampal neurons. J Cell Biol 18:1423-1434.

Enderlin S, Norman AW, Celio MR (1987) Ontogeny of the calcium binding protein calbindin D-28k in the rat nervous system. Anat Embryol 177:15-28.

Ernfors P, Ibanez CF, Ebendal T, Olson L, Persson H (1990a) Molecular cloning and neurotrophic activities of a protein with structural similar- ities to nerve growth factor: developmental and topographical expression in the brain. Proc Natl Acad Sci USA 87:5454-5458.

Ernfors P, Wetmore C, Olson L, Persson H (1990b) Identification of cells in rat brain and peripheral tissues expressing mRNA for members of the nerve growth factor family. Neuron 5:511-526.

Ernfors P, Lee KF, Kucera J, Jaenisch R (1994) Lack of neurotrophin-3 leads to deficiencies in the peripheral nervous system and loss of limb proprioceptive afferents. Cell 77:503-512.

Ghosh A, Carnahan J, Greenberg ME (1994) Requirement for BDNF in activity-dependent survival of cortical neurons. Science 263:1618-1623.

Giehl KM, Schutte A, Mestres P, Yan Q (1998) The survival-promoting effect of glial cell line-derived neurotrophic factor on axotomized corticospinal neurons in vivo is mediated by an endogenous brainderived neurotrophic factor mechanism. J Neurosci 18:7351-7360.

Greaves AA, Davis AK, Dallman JE, Moody WJ (1996) Co-ordinated modulation of $\mathrm{Ca}^{2+}$ and $\mathrm{K}^{+}$currents during ascidian muscle development. J Physiol (Lond) 497:39-52.

Henderson LP, Spitzer NC (1986) Autonomous early differentiation of neurons and muscle cells in single cell cultures. Dev Biol 113:381-387.

Iacopino AM, Christakos S (1990) Specific reduction of calcium-binding protein (28-kilodalton calbindin-D) gene expression in aging and neurodegenerative diseases. Proc Natl Acad Sci USA 87:4078-4082.

Ip N Y, Li Y, Yancopoulos GD, Lindsay RM (1993) Cultured hippocampal neurons show responses to BDNF, NT-3, and NT-4, but not NGF. J Neurosci 13:3394-3405.

Katz LC, Shatz CJ (1996) Synaptic activity and the construction of cortical circuits. Science 274:1133-1138.

Klein R, Silos-Santiago I, Smeyne RJ, Lira SA, Brambilla R, Bryant S, Zhang L, Snider WD, Barbacid M (1994) Disruption of the neurotrophin-3 receptor gene trkC eliminates la muscle afferents and results in abnormal movements. Nature 368:249-251.

Kokaia Z, Bengzon J, Metsis M, Kokaia M, Persson H, Lindvall O (1993) Coexpression of neurotrophins and their receptors in neurons of the central nervous system. Proc Natl Acad Sci USA 90:6711-6715.

Komuro H, Rakic P (1998) Orchestration of neuronal migration by activity of ion channels, neurotransmitter receptors, and intracellular $\mathrm{Ca}^{2+}$ fluctuations. J Neurobiol 37:110-130.

Korhonen L, Sjoholm U, Takei N, Kern MA, Schirmacher P, Castren E, Lindholm D (2000) Expression of c-Met in developing rat hippocampus: evidence for $\mathrm{HGF}$ as a neurotrophic factor for calbindin D-expressing neurons. Eur J Neurosci 12:3453-3461.

Korsching S (1993) The neurotrophic factor concept: a reexamination. J Neurosci 13:2739-2748.

Lamballe F, Smeyne RJ, Barbacid M (1994) Developmental expression of trkC, the neurotrophin-3 receptor, in the mammalian nervous system. J Neurosci 14:14-28.

Lewin GR, Barde YA (1996) Physiology of the neurotrophins. Annu Rev Neurosci 19:289-317.

Lindholm D, Carroll P, Tzimagiogis G, Thoenen H (1996) Autocrineparacrine regulation of hippocampal neuron survival by IGF-1 and the neurotrophins BDNF, NT-3 and NT-4. Eur J Neurosci 8:1452-1460.

Lo DC (1995) Neurotrophic factors and synaptic plasticity. Neuron 15:979-981.

Maisonpierre PC, Belluscio L, Friedman B, Alderson RF, Wiegand SJ, Furth ME, Lindsay RM, Yancopoulos GD (1990) NT-3, BDNF, and NGF in the developing rat nervous system: parallel as well as reciprocal patterns of expression. Neuron 5:501-509.

Marty S, Berninger B, Carroll P, Thoenen H (1996) GABAergic stimulation regulates the phenotype of hippocampal interneurons through the regulation of brain-derived neurotrophic factor. Neuron 16:565-570.

Mattson MP, Dou P, Kater SB (1988) Outgrowth-regulating actions of glutamate in isolated hippocampal pyramidal neurons. J Neurosci 8:2087-2100.

Mattson MP, Rychlik B, Chu C, Christakos S (1991) Evidence for calcium-reducing and excito-protective roles for the calcium-binding protein calbindin- $\mathrm{D}_{28 \mathrm{k}}$ in cultured hippocampal neurons. Neuron 6:41-51.

Meyer-Franke A, Wilkinson GA, Kruttgen A, Hu M, Munro E, Hanson Jr MG, Reichardt LF, Barres BA (1998) Depolarization and cAMP elevation rapidly recruit TrkB to the plasma membrane of CNS neurons. Neuron 21:681-693.

Miranda RC, Sohrabji F, Toran-Allerand CD (1993) Neuronal colocalization of mRNAs for neurotrophins and their receptors in the developing central nervous system suggests a potential for autocrine interactions. Proc Natl Acad Sci USA 90:6439-6443.

Moody WJ (1998) Control of spontaneous activity during development. J Neurobiol 37:97-109.

Pettmann B, Henderson CE (1998) Neuronal cell death. Neuron 20:633-647.

Phillips HS, Hains JM, Armanini M, Laramee GR, Johnson SA, Winslow JW (1991) BDNF mRNA is decreased in the hippocampus of individuals with Alzheimer's disease. Neuron 7:695-702.

Schecterson LC, Bothwell M (1992) Novel roles for neurotrophins are 
suggested by BDNF and NT-3 mRNA expression in developing neurons. Neuron 9:449-463.

Spitzer NC (1994) Spontaneous $\mathrm{Ca}^{2+}$ spikes and waves in embryonic neurons: signaling systems for differentiation. Trends Neurosci 17:115-118.

Tanaka O, Sakagami H, Kondo H (1995) Localization of mRNAs of voltage-dependent $\mathrm{Ca}^{2+}$-channels: four subtypes of alpha 1- and betasubunits in developing and mature rat brain. Brain Res Mol Brain Res 30:1-16.

Thoenen H (1995) Neurotrophins and neuronal plasticity. Science 270:593-598.

Vahedi K, Joutel A, Van Bogaert P, Ducros A, Maciazeck J, Bach JF, Bousser MG, Tournier-Lasserve E (1995) A gene for hereditary paroxysmal cerebellar ataxia maps to chromosome 19p. Ann Neurol 37:289-293.

Valmier J, Mallie S, Baldy-Moulinier M (1993) Skeletal muscle extract and nerve growth factor have developmentally regulated survival pro- moting effects on distinct populations of mammalian sensory neurons. Muscle Nerve 16:397-403.

Vicario-Abejon C, Johe KK, Hazel TG, Collazo D, McKay RD (1995) Functions of basic fibroblast growth factor and neurotrophins in the differentiation of hippocampal neurons. Neuron 15:105-114.

Vicario-Abejon C, Collin C, McKay RD, Segal M (1998) Neurotrophins induce formation of functional excitatory and inhibitory synapses between cultured hippocampal neurons. J Neurosci 18:7256-7271.

Von Brederlow B, Hahn AF, Koopman WJ, Ebers GC, Bulman DE (1995) Mapping the gene for acetazolamide responsive hereditary paryoxysmal cerebellar ataxia to chromosome 19p. Hum Mol Genet 4:279-284.

Wright EM, Vogel KS, Davies AM (1992) Neurotrophic factors promote the maturation of developing sensory neurons before they become dependent on these factors for survival. Neuron 9:139-150.

Yang XM, Toma JG, Bamji SX, Belliveau DJ, Kohn J, Park M, Miller FD (1998) Autocrine hepatocyte growth factor provides a local mechanism for promoting axonal growth. J Neurosci 18:8369-8381. 